\title{
CARACTERÍSTICAS DE QUALIDADE DE CULTIVARES DE MAÇÃ: AVALIAÇÃO FÍSICO-QUÍMICA E SENSORIAL DE QUINZE CULTIVARES ${ }^{1}$
}

\author{
Gilvan WOSIACKI ${ }^{2, *}$, Betânia Cristine PHOLMAN², Alessandro NOGUEIRA²
}

\begin{abstract}
RESUMO
Neste trabalho são apresentados aspectos de qualidade de interesse industrial de 15 cultivares de maçãs. A análise sensorial das frutas in natura discriminou as amostras de Melrose, Fred Housh, M 51/90 e Malus 71/90 como capazes de promover o processo de compra e de instalação do hábito de consumo. A análise sensorial dos sucos de frutas discrimina apenas a cultivar comercial Belgolden como interessante. Os sucos feitos com as amostras de maçãs apresentaram uma variação de 12 a $16^{\circ}$ BRIX e o valor médio de ácido málico foi de $0,362 \mathrm{~g} / 100 \mathrm{~mL}$. Os teores de compostos fenólicos apresentaram uma média de $316 \mathrm{mg} / \mathrm{L}$ e um desvio padrão de $70 \mathrm{mg} / \mathrm{L}$ (C.V.= $22 \%$ ). Os indicadores industriais são elevados demais para serem comparados com aqueles necessários, abaixo de 20/25; os valores médios encontrados neste conjunto de maçãs foram de 45 (indice BRIX/acidez) e 40,2 (indice ART/acidez). As amostras codificadas foram categorizadas como amargas, com um grupo de doces-amargas (as comerciais Fred Housh, Marquesa, Sansa e Romu, e as experimentais M 51/90 e todas as Malus) e outro de ácidas-amargas (as demais cultivares estudadas). As amostras mais interessantes para o processamento industrial de suco clarificado são a Belgolden, as Coop 25 e 26, a Melrose e a Malus 67/90). A Sansa desponta como portadora de maior teor de frutose e potencialmente como matéria-prima para a elaboração de bebidas com apelo funcional.

Palavras-chave: acidez; fenóis; suco de maçã; frutose.
\end{abstract}

\section{SUMMARY}

QUALITY PROFILE OF 15 APPLE CULTIVARS. The article shows some figures concerning industrial aplications of samples from apple cultivars. Sensorial evaluation of the apples in natura indicated Melrose, Fred Housh, M 51/90 and Malus 71/90 as able to satisfy the consumer. Sensorial evaluation of the apple juice shows only one interesting variety, Belgolden. The juices showed 12 to $16^{\circ} \mathrm{BRX}$ and a mean value of malic acid of $0,362 \mathrm{~g} / 100 \mathrm{~mL}$. Total phenol compounds showed a mean of $316 \mathrm{mg} / 1(\mathrm{C} . \mathrm{V} .=22 \%)$. Ratios concerning total sugar or total soluble solids: malic acid were too high as compared with the value $20 / 25$ necessary to industrial process. The apple samples were all characterized as bitter, with a set of bitter sweet (Fred Housh, Marquesa, Sansa, Romu, M 51/90 and all Malus) and another of bitter sharp (the others). The most interesting samples for industrial utilization are Belgolden, Coop 25 and 26, Melrose and Malus 67/90). The variety Sansa shows the highest level of fructose and it is an interesting raw material for functional drinks.

Keywords: acidity; phenol; apple juice; fructose.

\section{1 - INTRODUÇÃO}

O setor agrícola de produção de maçã nos Estados do Sul do Brasil abastece quantitativamente o mercado nacional e participa de processos de exportação da fruta para os entrepostos holandeses, competindo em ambos os casos com tradicionais exportadores, como a Argentina e a Nova Zelândia [12, 15]. No cenário mundial já se classifica em 5o lugar quanto à qualidade de produção e em 7o lugar quanto à infraestrutura disponivel embora contribua com apenas $1,5 \%$ da produção geral (www.abpm.br).

O abastecimento do mercado interno, face ao nível de exigência do consumidor brasileiro, mobiliza um procedimento agroindustrial de beneficiamento rigoroso que desqualifica cerca de $30 \%$ da produção, compreendendo as denominadas maçãs industriais e o descarte propriamente dito. A perspectiva de disponibilização de 250.000 toneladas de maçãs industriais na safra agrícola de 2004 pressiona o setor agroindustrial de maçãs a se voltar para procedimentos de agregação de valor à matéria-prima com a produção de sucos concentrados e

\footnotetext{
Recebido para publicação em 16/07/2002. Aceito para publicação em 09/06/2004 (000940).

2. Departamento de Zootecnia e Tecnologia de Alimentos, Universidade Estadual de Ponta Grossa, Caixa Postal 992. Ponta Grossa-PR. CEP: 84.030-900.

* A quem a correspondência deve ser enviada.
}

produtos fermentados tanto para o atendimento ao mercado interno quanto para o exterior. Processos de reconversão em unidades industriais já são observados $[10,13]$ e os beneficios para o comércio varejista se fazem notar com o surgimento de produtos nacionais nas gôndolas de sucos e de sidras.

A matéria-prima a ser disponibilizada compõe-se praticamente da classe industrial das cultivares Gala e Fuji, que juntas constituem hoje cerca de $95 \%$ da produção brasileira e fazem parte do conjunto de maçãs mais importantes em termos mundiais $[14,15,16]$. Entretanto, para o processamento industrial, estas cultivares deixam a desejar tanto no que diz respeito aos teores de componentes fenólicos quanto aos de acidez total titulável; são classificadas como doces-amargas [16] e para finalidades industriais precisam ser misturadas com outras cultivares, mais amargas e mais ácidas [8]. Amostras de maçãs comerciais e industriais têm sido avaliadas visando estabelecer o perfil de qualidade e identificando as melhores cultivares para uso industrial $[2,11]$.

Face aos novos paradigmas, o setor agro-industrial de maçã, que ora se serve das maçãs desqualificadas para consumo in natura como matéria-prima, passa a perceber a necessidade de implantar pomares industriais. Estes pomares, para atender as finalidades do setor de transformação, devem ser constituídos de cultivares adaptadas às condições edafoclimáticas e apresentar vantagens como maior produtividade, produtos 
mais adequados quanto ao tamanho, mediante um manejo mais simples e menos dispendioso.

De qualquer forma, sua existência não impede que as maçãs conhecidas como "industriais" atualmente possam ser utilizadas no processamento de sucos e de bebidas fermentadas. Assim como o setor de pesquisa agrícola contribuiu, há duas décadas, subsidiando tecnicamente a implantação de pomares comerciais, com o rigor da técnica e com o apoio de organizações americanas, japonesas e alemãs, pode voltar-se hoje à busca de cultivares de maçãs que possam ser industrializadas com sucesso. Além de bens econômicos de elevado valor como suco concentrado ou fermentado, não são descartados também os processos voltados à empresa rural de menor porte com uma ampla variedade de produtos, como doces, conservas, cascas ou fatias desidratadas, por exemplo.

$\mathrm{Na}$ avaliação de cultivares de maçãs há necessidade de observar a conjuntura tanto nos aspectos da globalização da economia e alargamento de fronteiras comerciais, favorecedores da comercialização de produtos com garantia de qualidade, quanto nas inovações observadas nos procedimentos tecnológicos. A extractabilidade do suco, por exemplo, deixou de ser um atributo crítico haja vista a possibilidade de usar água como agente de extração na produção de suco concentrado ou de enzimas que promovam a total liquefação dos polissacarideos presentes na fruta.

Neste trabalho apresentam-se os resultados da avaliação 15 amostras de cultivares de maçãs obtidas da coleção da Estação Experimental de Caçador da Empresa de Pesquisa Agropecuária - EPAGRI objetivando divulgar a metodologia de classificação das frutas e inferir suas melhores aplicações, com critérios aceitos internacionalmente.

\section{2 - MATERIAL E MÉTODOS}

\section{1 - Material}

Amostras de maçãs (40kg; primeira classe) das cultivares, colhidas na fase mediana da sua safra por técnicos especializados, foram armazenadas sob atmosfera controlada, transportadas com veículo não refrigerado ao laboratório e mantidas a temperatura de $8^{\circ} \mathrm{C}$ overnight antes do processamento em nivel de bancada. Produtos químicos foram de qualidade pró-análise e as enzimas comerciais, cedidas pela NOVO Nordisk do Brasil. As amostras estudadas são provenientes de pomares comerciais assim como de plantas ainda codificadas como experimentais na coleção de macieiras da Estação Experimental de Caçador. Estas amostras estão codificadas na Tabela 1 para subsidiar o entendimento dos resultados apresentados em gráficos ou tabelas.

\section{2 - Métodos}

O suco de maçã foi elaborado de acordo com o processamento convencional em laboratório compreenden- do as etapas de beneficiamento, processamento e conservação. Análises microbiológicas foram feitas para comprovar a eficácia do tratamento térmico. As análises de $\mathrm{pH}$, de sólidos solúveis totais, de acidez total titulável, de teores de açúcares totais, redutores e glucose, de compostos fenólicos e de número de formol foram determinados de acordos com técnicas oficiais $[5,9]$. Os indicadores de qualidade para industrialização foram calculados de acordo com os procedimentos usuais no setor industrial europeu [11]. A análise sensorial compreendeu os atributos aparência, sabor e aroma, tanto dos frutos quanto dos sucos, e foi feita com uma escala hedônica estruturada de 9 pontos [4] por um grupo de provadores não treinado nunca inferior a 30 componentes. Os resultados foram tabelados e avaliados estatisticamente segundo software ESTATISTICA, por técnicas de análises convencional e multivariada.

TABELA 1. Codificação e classificação das amostras de maçãs.

\begin{tabular}{cccc}
\hline Número & Código & Cultivar & Classificação \\
\hline 01 & $\mathrm{~A}$ & Belgolden & ácida-amarga \\
02 & $\mathrm{~B}$ & Coop 25 & ácida-amarga \\
03 & $\mathrm{C}$ & Coop 26 & ácida-amarga \\
04 & $\mathrm{D}$ & Fred Housh & doce-amarga \\
05 & $\mathrm{E}$ & M-51/90 & doce-amarga \\
06 & $\mathrm{~F}$ & Melrose & ácida-amarga \\
07 & $\mathrm{G}$ & Marquesa & doce-amarga \\
08 & $\mathrm{H}$ & Sansa & doce-amarga \\
09 & $\mathrm{I}$ & Romu 50 & doce-amarga \\
10 & $\mathrm{~J}$ & Malus 67/90 & ácida-amarga \\
11 & $\mathrm{~K}$ & Malus 71/90 & doce-amarga \\
12 & $\mathrm{~L}$ & Malus 72/90 & doce-amarga \\
13 & $\mathrm{M}$ & Malus $92 / 90$ & doce-amarga \\
14 & $\mathrm{~N}$ & Malus $94 / 90$ & doce-amarga \\
15 & $\mathrm{O}$ & Malus 59/91 & doce-amarga \\
\hline
\end{tabular}

\section{3 - RESULTADOS E DISCUSSÃO}

As amostras estudadas relacionadas na Tabela 1 representam cultivares comerciais, produtoras ou polinizadoras e experimentais. Algumas delas já são conhecidas pelos consumidores de maçãs. As maçãs da cultivar Belgolden são comercializadas usualmente junto com a Golden delicious, frutas que atingem baixo valor no mercado devido principalmente ao russeting, defeito físiológico típico na região peduncular. A Melrose comercial caracteriza-se pelo seu tamanho grande, atípico, prejudicial com relação ao aroma da fruta uma vez que a maior quantidade dos constituintes voláteis concentra-se na epiderme. A Marquesa e a Sansa, precoces, estão sendo incorporadas aos pomares comerciais a partir do final da década de 90 e são ainda pouco difundidas no mercado consumidor. As demais cultivares abordadas neste artigo estão ainda sob avaliação agronômica. 
Com relação ao primeiro quesito, que na prática define "o processo de compra", as amostras das cultivares Fred Housh, a M-51/90, a Melrose, a Marquesa e a Malus $71 / 90$ foram qualificadas no nivel "gostei muito", ou seja, seriam certamente compradas. Todas as demais amostras avaliadas receberam notas que não as recomendariam como cultivares com apelo comercial, inclusive a Belgolden, o que vem de encontro à atual tendência de expurgo desta cultivar de pomares comerciais. Os resultados das análises das frutas no quesito aroma foram bastante homogêneos qualificando-as, todas, como "gostei ligeiramente", ou seja, um nivel acima do "indiferente". Da mesma forma, o quesito sabor da fruta foi bastante homogêneo mas com um nivel superior, qualificando-as como "gostei regularmente"; os maiores escores, que as qualificariam como "gostei muito" e que definiriam "o hábito de compra", foram alcançados apenas pelas amostras de M-51/90 e Malus 71/90. Assim, a avaliação sensorial das frutas define de uma forma geral estas duas cultivares ainda experimentais como as mais promissoras do ponto de vista comercial.

A Figura 1 apresenta a dispersão dos escores dados pelos provadores nos quesitos aparência e sabor das frutas, destacando as cultivares M 51/90, Malus 71/90, Melrose e Fred Housh.

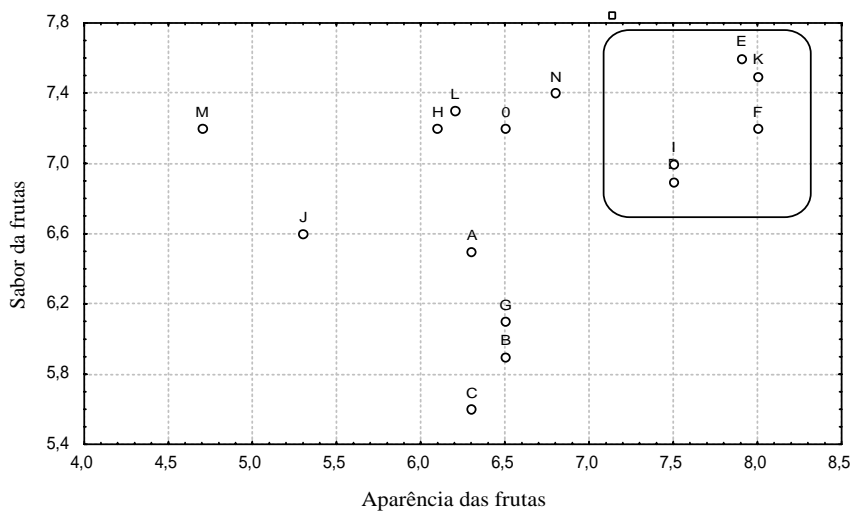

FIGURA 1. Discriminação das frutas em função das notas atribuídas pelos provadores nos quesitos aparência e sabor (para decodificação vide Tabela 1).

Os resultados da avaliação sensorial dos sucos clarificados das amostras indicam as cultivares Belgolden e Fred Housh com um nivel de aparência "gostei muito", sobressaindo-se de todas as demais amostras. O quesito "aroma do suco" não destacou nenhuma amostra do conjunto, qualificado como "gostei ligeiramente", o mesmo ocorrendo com o quesito "sabor do suco", qualificado como "gostei regularmente". Assim, pode-se inferir que estas frutas não apresentam condições suficientes para promover por si só o processo de compra no mercado varejista brasileiro a julgar por um limiar de valor sensorial 7 (gostei regularmente); pode ser inferido destas análises que as frutas não são atrativas e os sucos não são saborosos o suficiente para promover o comércio por si próprios, salvo algumas exceções.

A Figura 2 apresenta os resultados das análises sensoriais com relação aos sucos clarificados, indican- do a maioria num patamar abaixo de "gostei ligeiramente", alguns próximos da situação de "indiferença".

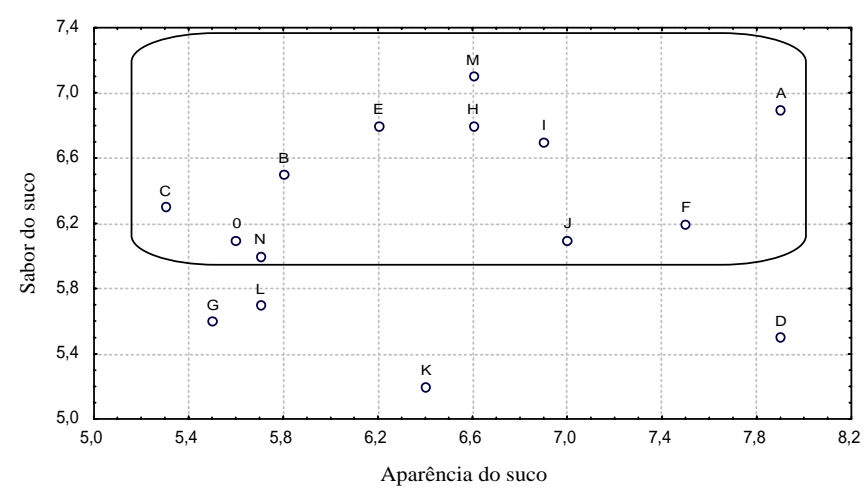

FIGURA 2. Discriminação dos sucos em função das notas atribuídas pelos provadores nos quesitos aparência e sabor (para decodificação vide Tabela 1).

Em atenção ao fato de que estas cultivares estão sendo estudadas em termos agronômicos para atender o mercado consumidor de frutas de mesa foram feitas avaliações sensoriais das maçãs in natura considerando como indicadores de qualidade a aparência, o aroma e o sabor (Tabela 2).

TABELA 2. Estatística simples dos resultados sensoriais

\begin{tabular}{lcccccccc}
\hline \multicolumn{1}{c}{ Variável } & $\mathrm{N}$ & $\begin{array}{c}\text { Valor } \\
\text { Mínimo }\end{array}$ & $\begin{array}{c}\text { Confiança } \\
-95 \%\end{array}$ & $\begin{array}{c}\text { Valor } \\
\text { Média }\end{array}$ & $\begin{array}{c}\text { Confiança } \\
+95 \%\end{array}$ & $\begin{array}{c}\text { Valor } \\
\text { Máximo }\end{array}$ & $\begin{array}{c}\text { Desvio } \\
\text { Padrão }\end{array}$ & $\begin{array}{c}\text { C.V. } \\
\%\end{array}$ \\
\hline \multicolumn{7}{c}{ Análise das frutas in natura } \\
Aparência & 15 & 4,7 & 6,14 & 6,67 & 7,21 & 8,00 & 0,97 & 14,54 \\
Aroma & 15 & 5,0 & 5,60 & 5,89 & 6,18 & 6,80 & 0,53 & 8,99 \\
Sabor & 15 & 5,6 & 6,54 & 6,88 & 7,22 & 7,60 & 0,61 & 8,89 \\
\hline \multicolumn{7}{c}{ Análise dos sucos } \\
\hline Aparência & 15 & 5,3 & 5,96 & 6,44 & 6,92 & 7,90 & 0,86 & 13,35 \\
Aroma & 15 & 5,6 & 6,04 & 6,26 & 6,48 & 6,90 & 0,40 & 6,39 \\
Sabor & 15 & 5,2 & 5,92 & 6,23 & 6,55 & 7,10 & 0,57 & 9,15 \\
\hline
\end{tabular}

Os resultados das análises físico-químicas, tratados estatisticamente, estão apresentados na Tabela 2 e compreendem as médias e respectivos desvios assim como a amplitude e o intervalo de confiança a 95\%. A análise de correlação apresentou uma matriz que discrimina as variáveis consideradas puras das derivadas e oferece suporte para o estabelecimento do grau de importância relativo.

Os teores dos compostos fenólicos não apresentam correlação com nenhuma das demais variáveis e por isto podem ser utilizados como indicadores de qualificação das amostras de maçã. O mesmo acontece com os teores de ácido málico, que se correlaciona apenas com variáveis derivadas como os índices industriais aqui representados como a razão existente entre os teores de sólidos solúveis totais ou de açúcares redutores totais com o de ácido málico. Os teores de açúcares redutores totais apresentam uma correlação elevada com os teores de sólidos solúveis totais e com os de frutose total mas não com os demais parâmetros relacionados aos açúcares, o que pode ser explicado em termos de diferenças entre cultivares. 
Os compostos fenólicos estão relacionados aos princípios amargos da maçã e compreendem principalmente ácido clorogênico e seus ésteres entre muitos outros componentes [3]; expressos como catequinas e em ppm. Como os compostos fenólicos podem ser oxidados a estruturas melanoidínicas pelo sistema de polifenoloxidase intrínseco da fruta, contribuem, além da sensação amarga, com a modificação da aparência do suco. Assim, um teor intermediário de compostos livres ou oxidados fornece um conjunto harmônico desejável no produto [8].

O conjunto analisado, com uma amplitude que vai desde 213 a 418 ppm, apresentou um teor médio de 316 $\pm 71 \mathrm{ppm}$ ou $\mathrm{mg} / 1000 \mathrm{~kg}$, o que indica um coeficiente de variação superior a 20\%. Das amostras, apenas três cultivares experimentais apresentaram valores superiores a $400 \mathrm{ppm}$, porém todas com valores superiores a 200ppm, considerados mínimos do ponto de vista industrial. O conjunto compreende, pois, cultivares consideradas amargas [SCHOBINGER et al., 1995; LEA, 1995], com menor dispersão na intensidade deste atributo em comparação a outros conjuntos já relatados na literatura [WOSIACKI et al., 1996; 2001; 2002; CZELUSNIAK et al., 2003]. Os valores estão dentro do preconizado pela legislação [7] e são compativeis com os apresentados por BIRUS [1] embora esta comparação não tenha maiores conseqüências pois as cultivares e condições climáticas européias são diferentes das encontradas no Brasil. Este atributo, referendado pela análise de componentes principais, é importante na discriminação da qualidade físico-química das cultivares de maçãs e serve de referencial para as classificações das maçãs comerciais e industriais, na prática.

A acidez total titulável de 0,36 $\pm 0,16 \mathrm{~g} / 100 \mathrm{~mL}$ (C.V. $27,77 \%$ ) indica um conjunto mais homogêneo que o usual com relação a este atributo, com uma variabilidade que vai de 0,13 a 0,63g/100mL [WOSIACKI et al., 1996; 2001; 2002; CZELUSNIAK et al., 2003]. Este atributo também é importante na discriminação das cultivares de maçãs, na prática, sendo que sucos clarificados concentrados são comercializados apenas com elevados teores de ácido málico (www.fluitprocessing.de).

Com fundamentação nestes dois atributos de qualidade é possivel classificar as maçãs em quatro categorias [CZELUSNIAK et al., 2003], respeitando os limites preconizados na literatura especializada [SCHOBINGER et al., 1995; LEA, 1995] que indica o de 0,45g/100mL de ácido málico para discriminar as maçãs doces das ácidas, e o de 200ppm de catequina para discriminar as pouco amargas das amargas.

Na Figura 3 é apresentada a dispersão das cultivares estudadas com relação aos seus teores de acido málico e de compostos fenólicos e como resultado a sua classificação conforme apresentada na Tabela 1. Neste gráfico destacam-se as cultivares Belgolden, Coop 25 e 26, Melrose e Malus 72/90 como ácidas e amargas, mais interessantes para o setor agroindustrial.

Os teores de açúcares redutores totais apresentam-se com um valor médio de $11,78 \pm 1,28 \mathrm{~g} / 100 \mathrm{~mL}$ $(\mathrm{C} . \mathrm{V} .=10,87 \%)$ e pode ser considerado como intrínseco à cultivares uma vez que todas as frutas foram colhidas num estádio adequado de maturação. Não há correlação entre estes valores com os de açúcares redutores ou mesmo glucose, mas sim com os de frutose, livre ou combinada. De qualquer forma, os teores de açúcares redutores totais e sua distribuição sob a forma de sacarose, glucose e frutose são importantes dentre os atributos de qualidade por diferentes motivos. Para efeitos de consumo in natura a mistura conhecida tecnicamente como açúcar invertido proporciona à fruta o característico sabor doce de uma forma mais peculiar do que os componentes propriamente ditos. Para efeitos industriais quanto mais açúcar presente, melhor para o processo de fermentação ou para o de obtenção de sucos concentrados clarificados.

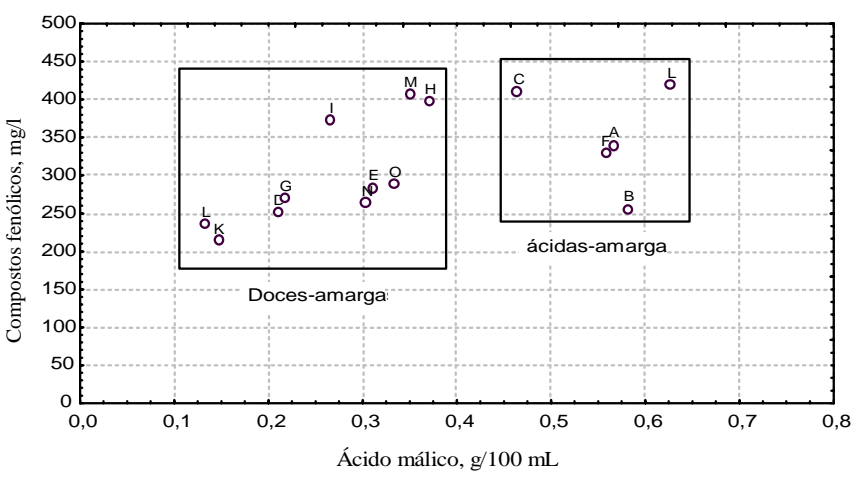

FIGURA 3. Classificação de maçãs em função de seus teores de componentes fenólicos e de ácido málico (para decodificação vide Tabela 1).

A Figura 4 apresenta a dispersão das cultivares em função dos teores de açúcares redutores totais e dos teores de ácido málico, sem maiores inferências a respeito da qualidade das amostras estudadas. Na realidade não há classificação de frutas segundo estes atributos, mas apenas a indicação das cultivares com maiores teores de açúcares, o que é importante: os maiores teores foram apresentados pela amostras das cultivares Sansa e Romu, comerciais, e as Malus, experimentais.

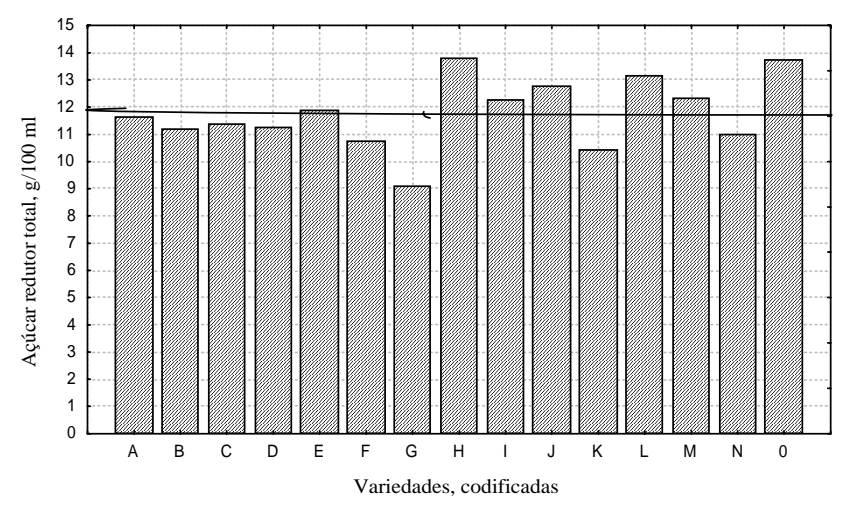

FIGURA 4. Apresentação dos teores de açúcares redutores totais das cultivares de maçãs (para decodificação vide Tabela 1). 
A utilização de um indicador que relacione estas duas características das maçãs parece ser mais adequada na discriminação das cultivares, e este atributo é a razão adimensional do teor de açúcares redutores totais e de ácido málico (IART), ou de sólidos solúveis totais e de ácido málico (BRX). O valor $20 / 25$ pode ser usado com certa parcimônia como limite para a discriminação das cultivares industriais, mais ácidas, das meramente comerciais, mais doces.

A Figura 5 apresenta a dispersão das cultivares com relação aos parâmetros compostos fenólicos totais e relação açúcar/ácido, identificando as mais interessantes para uso industrial, como sendo as comerciais Belgolden e Melrose e as experimentais Coop 25 e 26, e Malus 72/90.

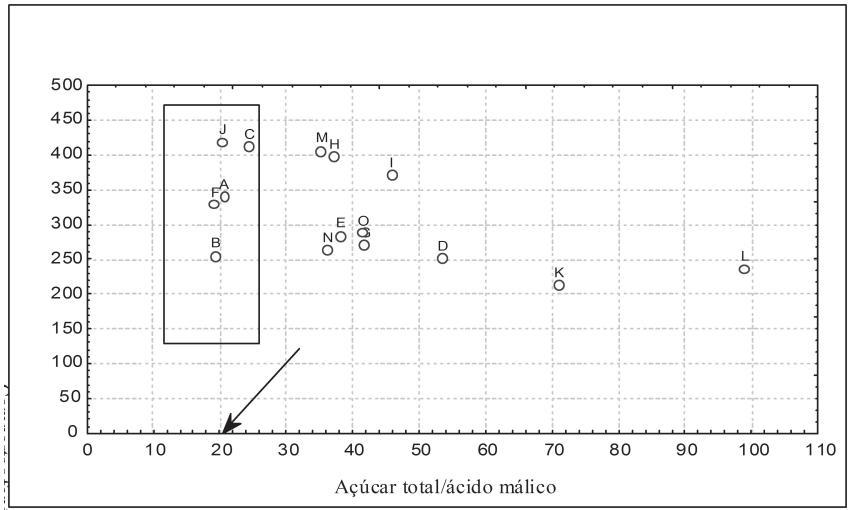

FIGURA 5. Classificação de maçãs em função de seus teores de compostos fenólicos totais e da razão entre os teores de açúcares totais e de ácido málico (para decodificação vide Tabela 1).

A discriminação das cultivares pelos teores de açúcares glucose e frutose está sendo proposta como um instrumento a mais na classificação de maçãs, fruta particularmente rica nesta cetose. A Figura 6 apresenta a dispersão das amostras de cultivares de acordo com estes dois açúcares e discrimina a cultivar Sansa como altamente promissora para uso em alimentos com apelo funcional pois apresenta cerca de $12 \%$ de frutose total, o que corresponde a $84 \%$ dos açúcares redutores totais da fruta.

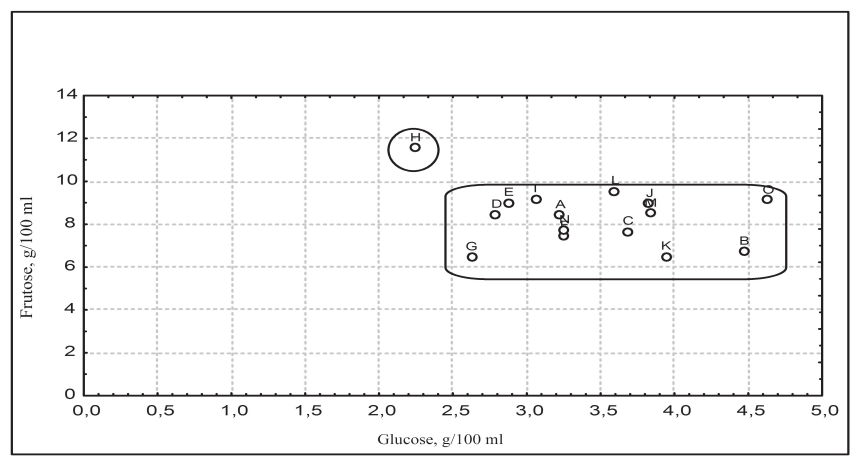

FIGURA 6. Classificação de maçãs em função dos teores de glucose e de frutose (para decodificação vide Tabela 1).
TABELA 3. Estatística simples das análises dos resultados físico-químicos.

\begin{tabular}{lcccccccc}
\hline \multicolumn{1}{c}{ Variável } & N & $\begin{array}{c}\text { Valor } \\
\text { Mínimo }\end{array}$ & $\begin{array}{c}\text { Confiança } \\
-95 \%\end{array}$ & $\begin{array}{c}\text { Valor } \\
\text { Média }\end{array}$ & $\begin{array}{c}\text { Confiança } \\
+95 \%\end{array}$ & $\begin{array}{c}\text { Valor } \\
\text { Máximo }\end{array}$ & $\begin{array}{c}\text { Desvio } \\
\text { Padrão }\end{array}$ & $\begin{array}{c}\text { C.V. } \\
\%\end{array}$ \\
\hline Comp.fenólico & 15 & 213 & 277 & 316 & 355 & 418 & 71 & 22,47 \\
Acidez total & 15 & 0,13 & 0,27 & 0,36 & 0,45 & 0,63 & 0,16 & 27,77 \\
Açúcar total & 15 & 9,10 & 11,07 & 11,78 & 12,48 & 13,80 & 1,28 & 10,87 \\
Açúcar redutor & 15 & 5,58 & 7,84 & 8,86 & 9,88 & 12,22 & 1,84 & 20,77 \\
Sacarose & 15 & 0,26 & 2,07 & 2,93 & 3,80 & 6,29 & 1,56 & 53,24 \\
Glucose & 15 & 1,15 & 1,66 & 1,96 & 2,26 & 2,93 & 0,54 & 25,55 \\
Glucose total & 15 & 2,24 & 3,05 & 3,42 & 3,79 & 4,63 & 0,67 & 19,60 \\
Frutose & 15 & 4,07 & 5,97 & 6,90 & 7,82 & 10,77 & 1,67 & 24,20 \\
Frutose total & 15 & 6,48 & 7,61 & 8,36 & 9,09 & 11,56 & 1,34 & 16,03 \\
Frutose/glucose & 15 & 1,51 & 2,09 & 2,57 & 3,04 & 5,16 & 0,74 & 27,40 \\
İndice BRIX & 15 & 22,74 & 31,97 & 45,11 & 58,00 & 104,00 & 23,75 & 52,65 \\
Índice IART & 15 & 19,21 & 28,21 & 40,20 & 52,19 & 99,00 & 21,66 & 53,88 \\
\hline
\end{tabular}

\section{4 - CONCLUSÕES}

A análise sensorial das frutas in natura discriminou as amostras das cultivares Melrose, Fred Housh, M 51/90 e Malus 71/90 como portadoras de apelo para promover o processo de compra e de instalação do hábito de consumo. A análise sensorial dos sucos de frutas discrimina apenas a cultivar comercial Belgolden como interessante. Se for desconsiderado o atributo aparência do sucos, as cultivares que receberam maiores notas no atributo sabor dos sucos foram as comerciais Sansa e Romu e as experimentais M 51/90 e Malus 92/90. Todas as cultivares foram classificadas como amargas, sendo que as comerciais Fred Housh, Marquesa, Sansa e Romu e as experimentais M 51/90 e todas as Malus fazem parte do conjunto das doces enquanto as demais, como ácidas. As cultivares discriminadas como interessante do ponto de vista industrial, por apresentarem valores do indicador próximo ao limite 20 são a Belgolden, as Coop 25 e 26, a Melrose e a Malus 67/90. A Sansa desponta como a portadora de maiores teores de frutose e potencialmente como matéria-prima para a elaboração de bebidas com apelo funcional.

\section{5 - REFERÊNCIAS BIBLIOGRÁFICAS}

[1] BIRUS, T. Moderne Apfelsaft Technologie. Flüssiges Obst GmbH: Schönborn, 2001.

[2] CZELUSNIAK, C.; OLIVEIRA, M.C.S.; NOGUEIRA, A.; SILVA, N.C.C.; WOSIACKI, G. Qualidade de maçãs comerciais produzidas no Brasil - Aspectos físico-químicos. Brazilian Journal of food Technology, Campinas, v. 6, p. 25-31, 2003.

[3] DIETRICH, H. Farb- und Gerbstoffe der Fruchtsäfte im Spannungsfeld verfahrerstechnicher und gesundheitlicher Aspekte. Flüssiges Obst, Schönborn, v. 64, n. 11, p. 631-637, nov. 1997.

[4] DUTCOSKI, S.D. Análise sensorial de alimentos. Curitiba: Univ. Champagnat, 1996.

[5] INSTITUTO ADOLFO LUTZ. Normas analiticas. São Paulo: IAL, 1976. v. 1, Métodos físicos e químicos para análise de alimentos.

[6] LEA, A. Cidermaking. Fruit Processing, Schönborn, v. 5, n. 9, p. 281-286, sep. 1995. 
[7] RSK WERTE. Richtwerte und Schwankungsbreiten bestimmter Kennzahlen mit überarbeiten Analysenmethoden. Bonn: Verband der deutschen Fruchtsaftindustrie, 1987.

[8] SCHOBINGER, U.; BARBIC, I.; DÜRR, P.; WALDVOGEL, R. Phenol compounds in apple juice. Positive and negativ effects. Fruit Processing, Schönborn, v. 5, n. 6, p. 171-178, jun.1995.

[9] TANNER, H.; BRUNNER, H.R. Getränke Analytik Untersuchungsmethode für die Labor- und Betriebspraxis. Schwäbische Hall: Heller Verlag, 1979.

[10] WOSIACKI, G.; CHERUBIM, R.A.; SANTOS, D.S. Cider Processing in Brazil. Fruit Processing, Schönborn, v. 7, n. 7, p. 242-249, ago. 1997.

[11] WOSIACKI, G.; CHERUBIM, R.A.; HILGEMBERG, C. Characterization of the apple juice from new varieties growing in Brazil. Fruit Processing, Schönborn, v. 6, n. 8, p. 306-310, ago. 1996.

[12] WOSIACKI, G.; CHIQUETTO, N.C.; KIRCHNER, C.L. Brazilian apple production, Fruit Processing, Schönborn, v. 3, n. 8, p. 277-283. ago. 1993.
[13] Wosiacki, G.; DemiAte, I.M.; CHERUBin, R.A, Brazilian Apple Juice Industry, Fruit Processing, Schönborn, v. 5, n. 5, p.10-14, mai. 1995.

[14] WOSIACKI, G.; NOGUEIRA, A. Apple varieties growing in subtropical áreas. The situation in Paraná - Brazil. Fruit Processing, Schönborn, v. 11, n. 5, p. 177-182, may, 2001.

[15] WOSIACKI, G.; NOGUEIRA, A.; SILVA, N.C.C. Brazilian apple production - a few years later. Fruit Processing, Schönborn, v. 10, n. 12, p. 472-475, dec. 2000.

[16] WOSIACKI, G.; NOGUEIRA, A.; Silva, N.C.C.; DENARDI, F.; CAMILO, A.P. Apple varieties growing in subtropical areas - The situation of Santa Catarina - Brazil. Fruit Processing, Schönborn, v. 12, n. 01, p. 19-28, jan. 2002.

\section{6 - AGRADECIMENTOS}

Os autores agradecem à Universidade Estadual de Ponta Grossa pela infraestrutura, ao CNPq pelas bolsas recebidas e à Estação Experimental de Caçador da EPAGRI pela amostras cedidas. 